\title{
TEM identification of subsurface phases in ternary U-Pu-Zr fuel
}

\author{
Assel Aitkaliyeva ${ }^{1}$, James W. Madden, Cynthia A. Papesch, James I. Cole \\ Idaho National Laboratory, Idaho Falls, ID, 83415
}

\section{Keywords}

Metallic fuel, transmission electron microscopy (TEM), electron diffraction

\begin{abstract}
Phases and microstructure in as-cast, annealed at $850^{\circ} \mathrm{C}$, and subsequently cooled U$23 \mathrm{Pu}-9 \mathrm{Zr}$ fuel were characterized using scanning and transmission electron microscopy techniques. SEM examination shows formation of three phases in the alloy that were identified in TEM using selective area diffraction pattern analysis: $\alpha$-Zr globular and elongated $\delta$ - $\mathrm{UZr}_{2}$ inclusions and a thick oxide layer formed on top of $\beta$-Pu phase, which has been initially assumed to be $\zeta-(\mathrm{U}, \mathrm{Pu})$. However, further examination of the cross-sectional TEM specimens identified the matrix phases as $\delta$ - $\mathrm{UZr}_{2}, \beta$-Pu, and $(\mathrm{U}, \mathrm{Zr}) \mathrm{ht}$. Two types of inclusions were observed in the immediate vicinity of the specimen surface and they were consistent with $\alpha-\mathrm{Zr}$ and $\zeta-(\mathrm{U}, \mathrm{Pu})$.
\end{abstract}

\section{Introduction}

Metallic fuels are considered for application in advanced fast reactors because of their high burn-up, high fissile and fertile density capability, and high thermal conductivity with significant safety benefits [1]. Metallic fuels have several potential advantages, such as simple fabrication, robust performance, benign response to reactor transients, and relatively easy recycling using compact molten salt electrochemical processing. The uranium-plutoniumzirconium ( $\mathrm{U}-\mathrm{Pu}-\mathrm{Zr}$ ) alloys are considered to be one of the most promising metallic fuels. The addition of $\mathrm{Zr}$ in U-Pu matrix was sought to increase the melting temperature of U-Pu alloys and to enhance compatibility between the fuel and stainless-steel cladding by suppressing the interdiffusion of fuel and cladding constituents during steady-state reactor operations.

Extensive studies have been carried out to understand fuel swelling, fuel performance during transients, failure mechanisms, behavior following benign failure and complete failure of fuel pins, and mechanical and chemical fuel-cladding interactions [2-4]. Constituent migration between radial zones of a cylindrical fuel element and their redistribution can lead to inhomogeneity of the initially uniformly mixed alloys. Inhomogeneity of metallic fuels can lead to phase transformations, solidus temperature change, and local changes in fissile atom density, which can alter mechanical and physical properties of the fuel and affect its behavior and

${ }^{1}$ Corresponding author

Idaho National Laboratory, P.O. Box 1625, M.S. 6188, Idaho Falls, ID 83415-6188, assel.aitkaliyeva@inl.gov, T: 208-533-8853, F: 208-533-7863. 
performance [4]. However, complete understanding of the irradiation behavior of U-Pu-Zr transmutation fuels cannot be achieved without accurate knowledge of the phases and microstructure of unirradiated fuels. Kurata has conducted a detailed thermodynamic assessment of the U-Pu-Zr system [5]. A detailed structural and chemical compositional analysis of phases formed in these fuel alloys is yet to be conducted.

Phases formed in Pu-based systems have been previously experimentally investigated using thermal analysis techniques, X-ray diffraction (XRD), and wavelength and energy dispersive spectroscopy (EDX/WDX) in scanning electron microscopes (SEM) [6-9]. The issue associated with both XRD and SEM analyses is that both techniques are surface-based. In addition, spatial resolution, magnification-dependent sensitivity of EDX/SEM, and overlap between $\mathrm{U}$ and $\mathrm{Pu}$ peaks in EDX results in questionable quantitative chemical analysis of $\mathrm{Pu}-$ based phases. To avoid such uncertainties, detailed structural and chemical composition analysis of phases and microstructure of $\mathrm{U}-23 \mathrm{Pu}-9 \mathrm{Zr}$ fuels has been conducted in the transmission electron microscope (TEM). The high spatial resolution of TEM allowed characterization of individual matrix phases. Selected-area electron diffraction (SAED) using transmission electron microscopy provided important space-group information and lattice parameters of the phases formed in ternary U-Pu-Zr system.

\section{Materials and methods}

The fuel alloy with nominal composition of $\mathrm{U}-23.3 \mathrm{Pu}-8.7 \mathrm{Zr}$ (in wt\%) was selected in this study. To simplify, the fuel alloy will be referred to as U-23Pu-9Zr. This fuel was a part of a larger specimen matrix in which both $\mathrm{Pu}$ and $\mathrm{Zr}$ compositions varied from 10 at $\%$ to 60 at $\%$. In this contribution, fuel with 20 at $\% \mathrm{Pu}$ composition and $20 \mathrm{at} \% \mathrm{Zr}$ composition was selected for examination ( $\mathrm{U}-20 \mathrm{Pu}-20 \mathrm{Zr}$ in at\%). The alloys were constituted by weighing out the raw materials in the proportions required to meet the desired fuel composition. Compositions of most alloys were verified using inductively coupled plasma-mass spectroscopy (ICP-MS).

The fuel was arc cast in an inert atmosphere glove box using a drop casting technique. The homogenization of the alloy was achieved by melting the alloy twice and inverting it before each melting. Final melting of the alloy was followed by casting of the alloy in a $\mathrm{ZrO}_{2}$ coated quartz tube, and dipping the tube into the molten liquid. The liquid was drawn up into the tube using a syringe. The slug dimensions for the cast fuel were approximately $5 \mathrm{~cm}$ in length and 4.9 $\mathrm{mm}$ in diameter. After casting, the alloy was annealed at $850^{\circ} \mathrm{C}$ for 96 hours followed by natural cooling in the furnace for one day. The specimen was allowed to cool to ambient temperature under argon flow. The cylindrical alloy slugs were sectioned into several samples designated for microstructural characterization. A transverse slice of the fuel was embedded in acrylic resin. The surface of fuel slug was polished through a $1 \mu \mathrm{m}$ diamond solution to a mirror polish prior to analysis. Since even ultra-high purity argon used during fabrication and annealing of the specimens can contain oxygen and other reacting gases, formation of oxides at the initial interface cannot be overruled. It is possible that the formed phases have been stabilized by impurities. 
Surface of the specimen was initially examined using EDX/WDX techniques in a JEOL JSM 7000F field emission SEM operated at accelerating voltage of $20 \mathrm{kV}$. SEM was used to examine the formed microstructure and determine the location of the phases of interest. To reduce charging in the SEM, a layer of Au coating was applied to the sample surface prior to the insertion into the instruments. Cross-sectional specimens for transmission electron microscopy (TEM) were prepared in a FEI QUANTA 3D field emission gun (FEG) dual beam focused ion beam/scanning electron microscope (FIB/SEM) using a lift-out approach. Specimens for transmission electron microscopy were characterized in a FEI Tecnai TF30-FEG STwin TEM operated at $300 \mathrm{kV}$.

\section{Results and discussion}

It has been previously shown that in the temperature range of $650-750^{\circ} \mathrm{C}, \mathrm{U}-\mathrm{Pu}-\mathrm{Zr}$ alloys consist of the bcc solid solution of the $\gamma-\mathrm{U}$ phase with dissolved $\mathrm{Pu}$ and $\mathrm{Zr}$ [9]. The bcc $\gamma$ phase exists in two-phase mixture with the tetragonal $\zeta-(\mathrm{U}, \mathrm{Pu})$ phase down to $600^{\circ} \mathrm{C}$ and transforms to the hexagonal $\delta-\mathrm{UZr}_{2}$ phase below $600^{\circ} \mathrm{C}$ [8]. At temperatures below $500^{\circ} \mathrm{C}, \zeta-(\mathrm{U}, \mathrm{Pu})$ phase rejects the orthorhombic $\alpha$ phase (U-Pu solid solution) $[8,10]$. The bcc $\gamma$ phase cannot be retained upon cooling of the alloy and it decomposes into $\zeta-(\mathrm{U}, \mathrm{Pu})$ and $\delta$ - $\mathrm{UZr}_{2}$ phases during cooling process [8].

The fuel alloy selected for this study was annealed at $850^{\circ} \mathrm{C}$ for 96 hours and was cooled to an ambient temperature in furnace under argon flow with heat turned off. The temperature drop was not monitored and kinetics of cooling process was not estimated. However, based on previous observation, cooling process was not rapid. Since the sample was not quenched to preserve phases formed at $850 \mathrm{C}$, phases formed in the specimen were non-equilibrium. Authors expected to observe remnants of high temperature phases with majority of the phases corresponding to low temperature and room temperature phases.

The extrapolated room temperature ternary U-Pu-Zr phase diagram in Fig. 1 suggests that there should be two predominant phases present in the alloy: the $\delta-\mathrm{UZr}_{2}$ and $\zeta-(\mathrm{U}, \mathrm{Pu})$, and possibly a small amount of $\alpha-\mathrm{U}$ phase. The $\delta-\mathrm{UZr}_{2}$ phase has an $\mathrm{AlB}_{2}$ type structure (hexagonal setting, $P 6 / \mathrm{mmm}$ space group), is non-stoichiometric, and should have extensive solid solubility for plutonium. The $\zeta-(\mathrm{U}, \mathrm{Pu})$ phase belongs to the $R-3 m$ space group with 58 atoms in the primitive unit cell and ten atoms in the asymmetric unit cell [11]. 


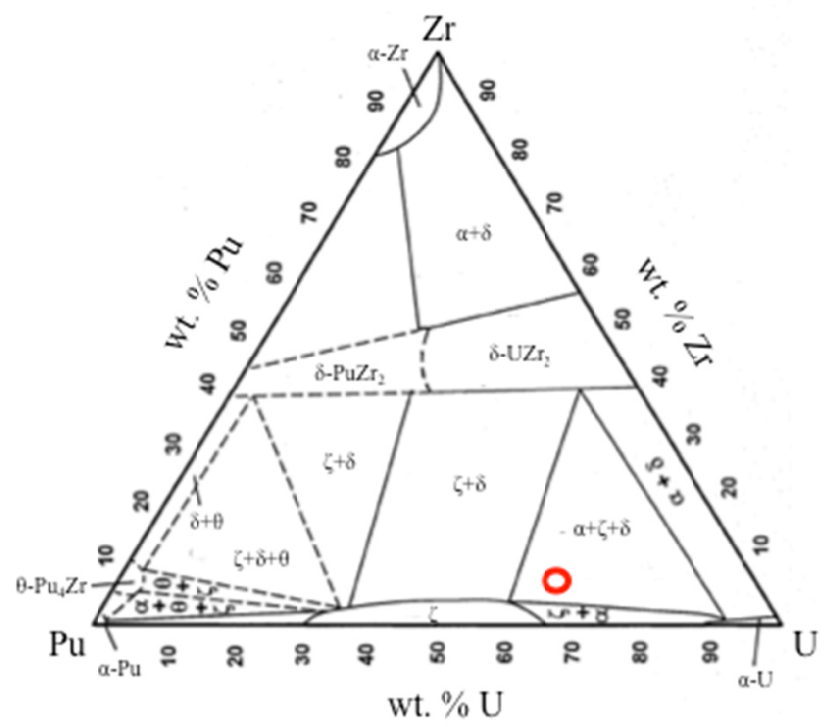

Figure 1. Extrapolated room temperature ternary U-Pu-Zr phase diagram [10]. The circle identifies compositional point of U-23Pu-9Zr fuel.

The room temperature X-ray diffraction (XRD) measurement conducted on an alloy with composition similar to U-23Pu-9Zr (U-24Pu-15Zr) identified the $\delta$ - $\mathrm{UZr}_{2}$ and $\zeta-(\mathrm{U}, \mathrm{Pu})$ phases, a small amount of non-equilibrium $\gamma$-U phase, and high weight fractions for $\alpha$-Zr on the order of $50 \mathrm{wt} \%$ [10]. Similarly to this study, the U-24Pu-15Zr alloy was made using an arc melter with the drop casting technique and was heat-treated at $850^{\circ} \mathrm{C}$ for 96 hours [10]. The presence of the observed high temperature $\gamma$-phase in the reported study was an indication of a non-equilibrium state formed upon rapid quenching of the cast alloys [10]. Further treatment most likely would have transformed the non-equilibrium metastable $\gamma$-U phase into equilibrium $\zeta-(\mathrm{U}, \mathrm{Pu})$ and $\delta$ $\mathrm{UZr}_{2}$ phases. Formation of an $\alpha-\mathrm{Zr}$ phase is not anticipated as it can be seen from the extrapolated room temperature phase diagram for the alloy composition under study (Fig. 1). However, Zr-rich phases, stabilized by dissolved impurities such as N, O, and C, were previously observed in a variety of transmutation fuels [8, 12-16]. These Zr-rich phases are assumed to be $\alpha-\mathrm{Zr}$ that formed during alloy preparation because of the interstitial impurities present in the feedstock [8]. Even so, existing phase diagrams indicate that the equilibrium room-temperature $\alpha-Z r$ phase should not form [12-16].

Evaluation of the isotherms for the ternary phase diagram confirms that upon cooling the $\mathrm{U}-23 \mathrm{Pu}-9 \mathrm{Zr}$ alloy should undergo four equilibrium phase transitions. The $\gamma-\mathrm{U}$ (U ht2-Pu ht5-Zr ht) phase transforms to $\gamma-\mathrm{U}$ with $\zeta-(\mathrm{U}, \mathrm{Pu})$ between 650 and $595^{\circ} \mathrm{C}$; to $\gamma-\mathrm{U}, \delta-\mathrm{UZr}_{2}$ and $\zeta-(\mathrm{U}, \mathrm{Pu})$ between 595 and $580^{\circ} \mathrm{C}$; then to $\delta-\mathrm{UZr}_{2}$ and $\zeta(\mathrm{U}, \mathrm{Pu})$ between 580 and $550^{\circ} \mathrm{C}$; and finally to $\alpha$ $\mathrm{U}, \delta-\mathrm{UZr}_{2}$ and $\zeta-(\mathrm{U}, \mathrm{Pu})$ at temperatures below $550^{\circ} \mathrm{C}[10-12]$. 

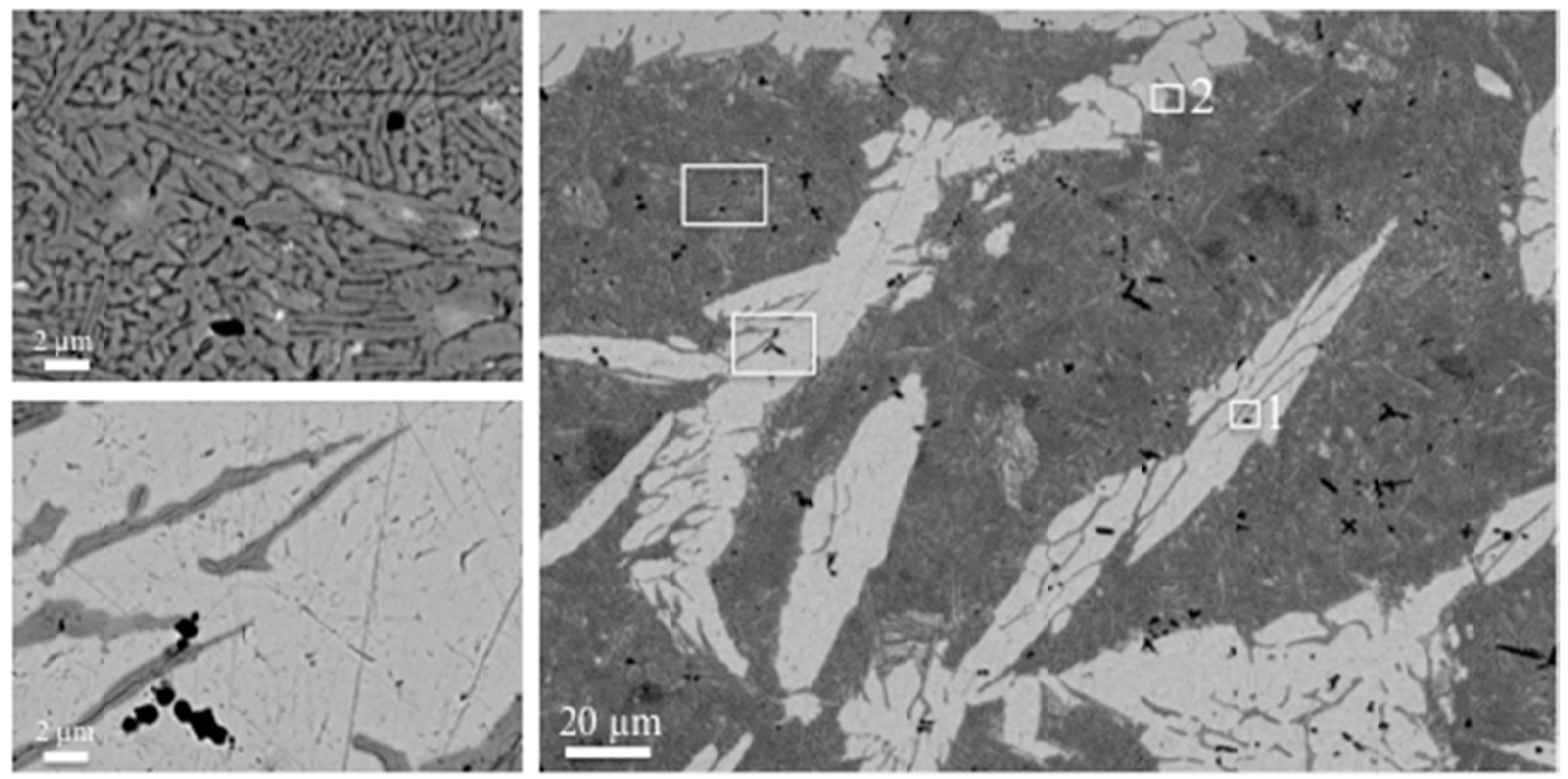

Figure 2. Backscattered electron (BSE) micrographs showing the microstructure of the fuel. Two BSE micrographs on the left are a higher magnification overview of the areas identified with white rectangles in the micrograph on the right. Two smaller rectangles identify positions of TEM lift-outs.

Figure 2 shows backscattered electron micrographs acquired from the surface of the fuel slug. Multiphase microstructure can be noted - inclusions with dark contrast, large light elongated features, and medium contrast textured matrix likely correspond to three different phases. These dark inclusions appear approximately uniform in size and shape throughout the sample and are distributed evenly. In addition, large, elongated light contrast features are uniformly distributed on the surface of the sample. EDX point scans and WDX maps were collected from each identified phase. However, unavailability of standards for transuranic elements in the EDX/WDX software prevented obtaining meaningful quantitative or semiquantitative compositional data and thus the results are represented in the form of qualitative Xray map data.

Figure 3 shows representative X-ray maps collected from the fuel surface. The WDX detector was used to produce maps of intensities of selected characteristic X-rays from each element individually. Light elements were collected using EDX detector. Each map was adjusted for contrast and brightness to emphasize spatial variations in intensity. Brighter areas in each map represent higher concentrations of the element of interest. Less bright areas in the same map indicate lower concentrations. Note that equally bright areas in different maps do not represent comparable concentrations. Dark globular inclusions correspond to the phase with high $\mathrm{Zr}$ content. Large, elongated light features correspond to phases enriched with both $U$ and $Z r$. The matrix has $U$ higher content. The $U$ concentration in the upper right region of the matrix is due to the lower number of frames collected for $\mathrm{U}$ in WDX as compared to Pu. Precise identification of the phases could not be carried out from qualitative X-ray maps shown in Fig. 3. 

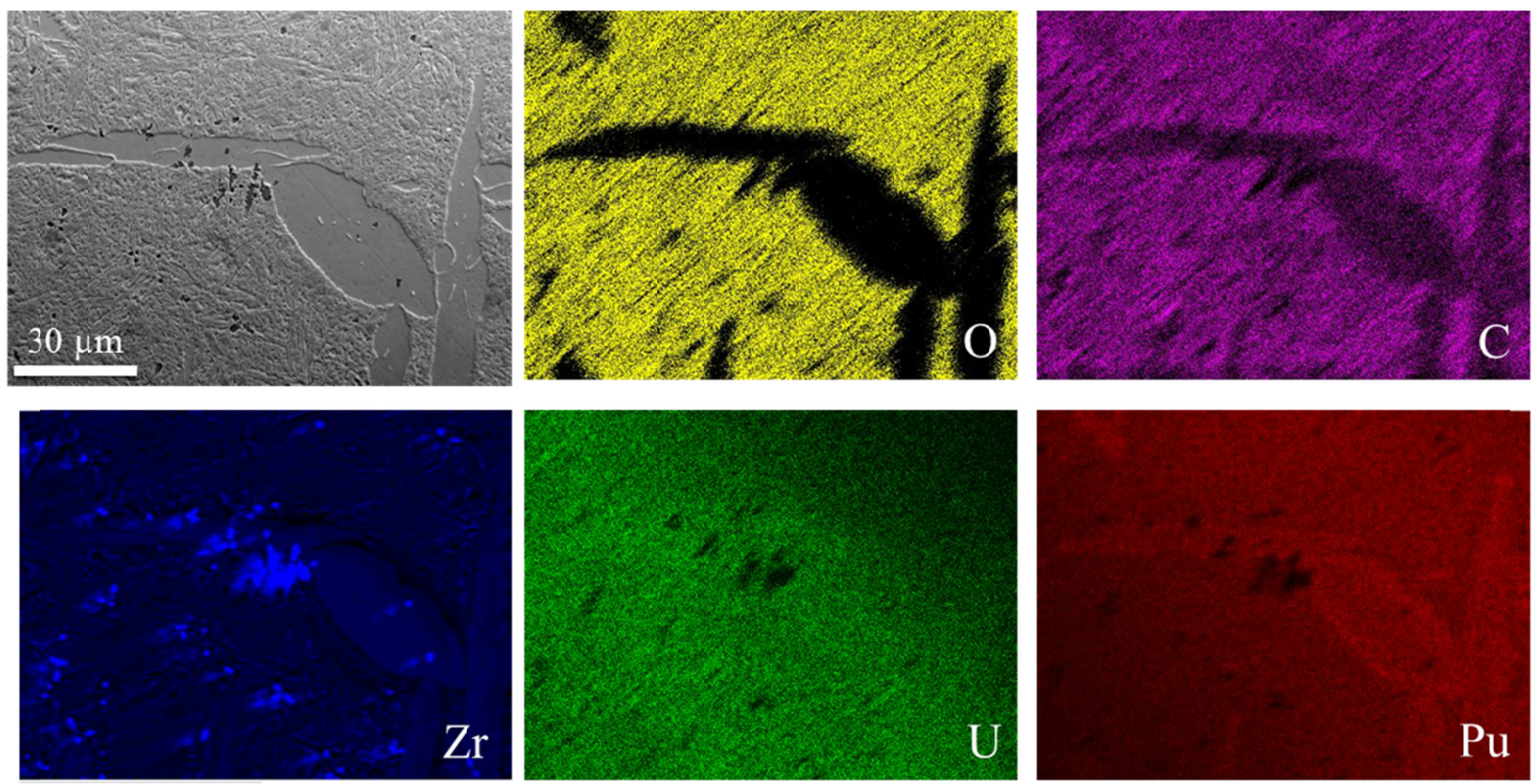

Figure 3. Scanning electron micrograph and corresponding X-ray maps of the phases formed in ternary U-23Pu-9Zr system.

Instead, identification of the formed phases was conducted in TEM by comparing experimental selective area electron diffraction (SAED) patterns to simulated patterns from published crystal structures produced using JEMS software [17]. In addition, $d$ spacing of each diffraction pattern was measured and compared to the published crystallographic data. Two cross-sectional TEM specimens (each approximately $15 \mu m \times 10 \mu m \times 0.1 \mu m$ in size) were prepared from two different locations within the specimen. Figure 4 shows scanning transmission electron micrographs acquired from the first cross-sectional specimen. The textured matrix observed during SEM analysis (Fig. 2) does not actually correspond to the matrix (Fig. 4). Red arrows in Fig. 4 indicate location of these textured features on the lamella. Based on TEM and scanning TEM (STEM) examination, the textured features observed on the surface of the parent sample are oxide layers formed on top of the specimen matrix. Several distinctive features were observed in the lamella and the bottom row of micrographs in Fig. 4 provides a higher magnification overview of those features. Since the specimens were prepared in a FIB, one could expect Ga beam damage and associated artifacts. However, examination in the TEM did not show any Ga ion beam-induced artifacts in the specimen, and no influence on the presented results was noted. 


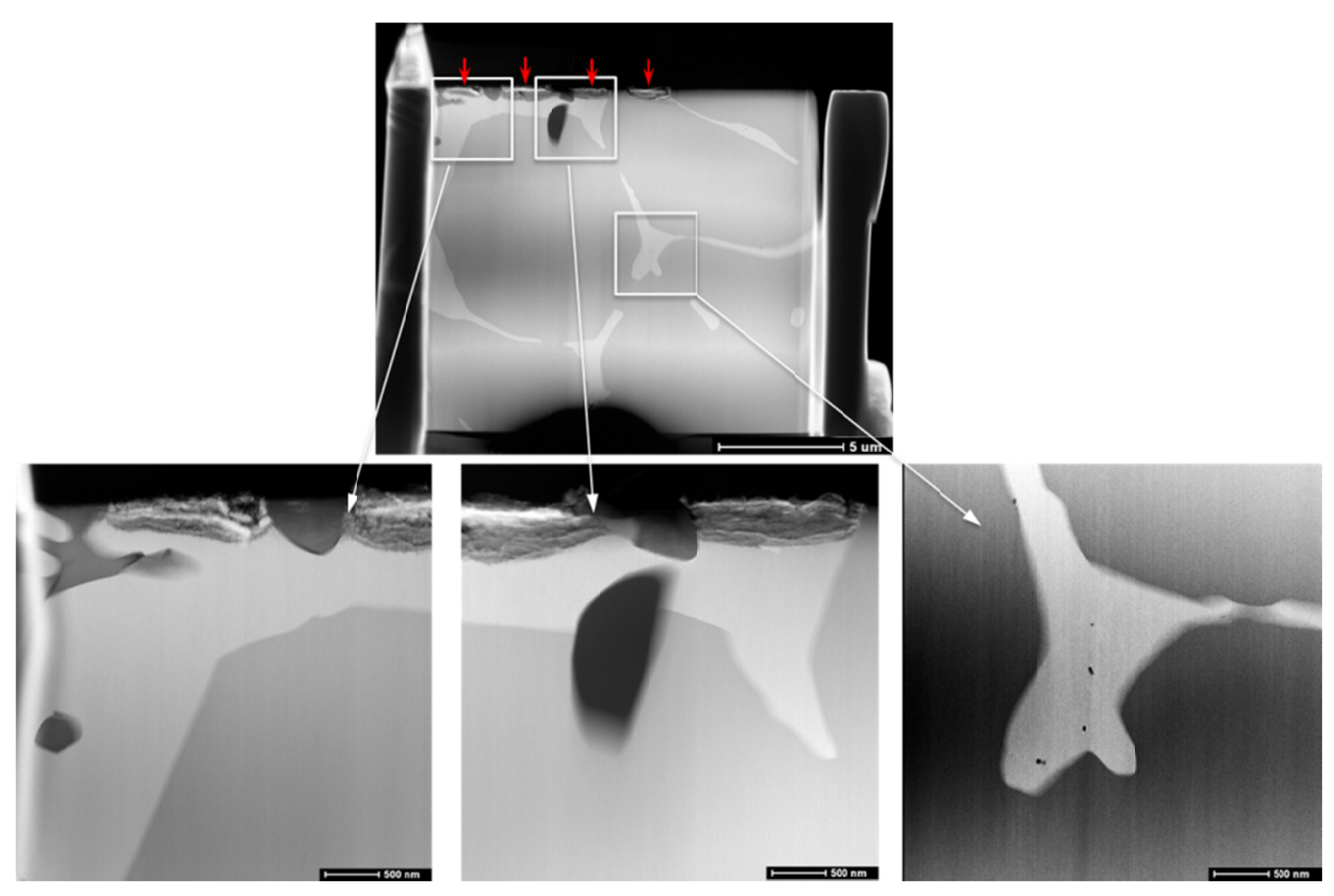

Figure 4. Scanning transmission electron micrographs providing an overview of the first crosssectional specimen lifted-out from U-23Pu-9Zr fuel. Red arrows indicate location of the oxide layer.

Based on the collected SAED patterns shown in Fig. 5, three features observed on the surface of the lamella in Fig. 4 (top left corner of the top micrograph) correspond to $\zeta$-(U, Pu) phase, $\delta$ - $\mathrm{UZr}_{2}$ phase, and a severely oxidized $\beta$-Pu phase. EDS point scan of the $\beta$-Pu phase showed up to 90 at $\%$ O. TEM examination shows that the textured features seen in Fig. 2 form only on $\beta$-Pu phase and not on $\delta$ - $\mathrm{UZr}_{2}$ phase. In fact, the light contrast elongated features seen in Fig. 2 are $\delta-\mathrm{UZr}_{2}$ phase, which oxidizes at slower rate than $\beta$-Pu. EDS point scan shows up to 35 at $\% \mathrm{O}$ in $\delta-\mathrm{UZr}_{2}$ phase. SAED analysis of the $\beta$-Pu phase formed on top of specimen surface showed partial amorphization of the phase. The surface $\beta$-Pu phase was studied in various locations and the $\beta$-Pu phase had amorphous nature when formed of the surface. The medium contrast globular features seen in the scanning transmission electron micrograph (Fig. 5) correspond to $\delta-\mathrm{UZr}_{2}$ phase, while the light matrix is consistent with $\beta$-Pu phase. Note that the oxidation layer that grew on top of $\beta$-Pu phase did not form on top of $\zeta-(\mathrm{U}, \mathrm{Pu})$ and $\delta$ $\mathrm{UZr}_{2}$ phases observed on the surface. Substantial oxidation of the $\delta-\mathrm{UZr}_{2}$ phase (up to 35 at $\% \mathrm{O}$ based on EDS results), seen in Fig. 5 and 6 is due to the specimen exposure to air during specimen transfer between instruments. Despite the efforts to promptly transfer samples to TEM upon unloading from the FIB, samples were exposed to air for $\sim 5$ minutes in order to take radiological smears from the equipment and follow safe radiological practices. 


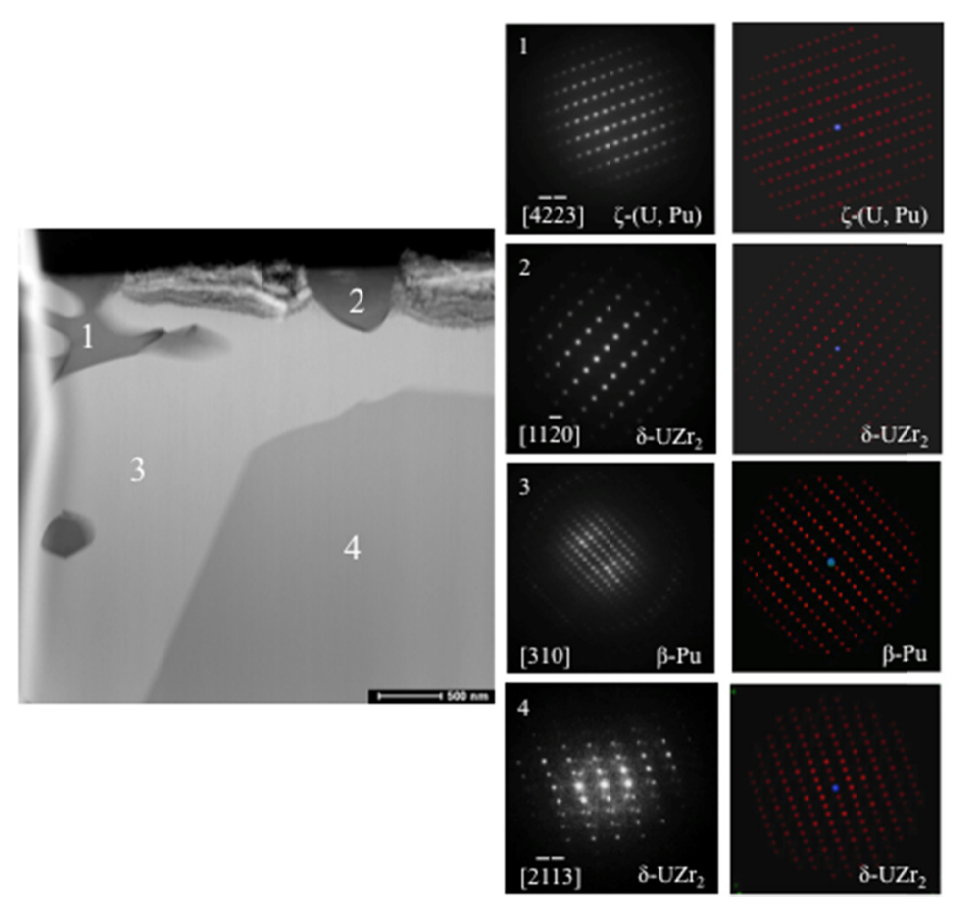

Figure 5. STEM micrograph acquired from the left hand side of first cross-sectional lift-out and corresponding experimental (middle row) and simulated SAED patterns (right row).

Figure 6 shows STEM micrograph and additional SAED patterns of phases identified from the first lift-out specimen. In addition to the identified $\zeta-(\mathrm{U}, \mathrm{Pu}), \delta-\mathrm{UZr}_{2}$, and $\beta-\mathrm{Pu}$ phases, $\alpha-Z r$ precipitate has been found. The dark contrast $\mathrm{Zr}$-enriched globular features observed on the surface of the specimen (Fig. 2) correspond to $\alpha$-Zr. These $\alpha$-Zr inclusions seem to be associated with the larger fraction of $\delta$ - $\mathrm{UZr}_{2}$ phase observed in the fuel. Previous studies indicated migration of zirconium to the surface of the sample during heat treatment, and separation of $\alpha-\mathrm{Zr}$ phase from the matrix to form a thin layer on the surface of the fuel [10]. It is believed that formation of oxygenated surface upon exposure of the sample to air, coupled with migration of $\mathrm{Zr}$ towards the oxygen upon heating of the specimen, results in formation of the $\alpha-\mathrm{Zr}$ [10]. Our study confirms this theory as we observe $\alpha$ - Zr precipitates in the immediate vicinity of the surface, where the passivation layer has formed prior to annealing.

Passivation will occur with fuels going into reactors, but it most likely will not affect the fuel performance significantly. SEM analysis of the fuel suggests formation of a large number of randomly distributed $\alpha-\mathrm{Zr}$ precipitates but the precipitates are small in size. However, passivation layers will influence bulk analysis techniques, such as XRD. The abundance of $\alpha-\mathrm{Zr}$ will diminish the equilibrium proportions of phases in XRD samples as the XRD data acquisition is confined to the surface of the fuel. These passivation layers will prevent measurement of the kinetics of phase transitions at high temperatures. The kinetics information is critical for developing scientific understanding and increasing fuel-modeling reliability. 


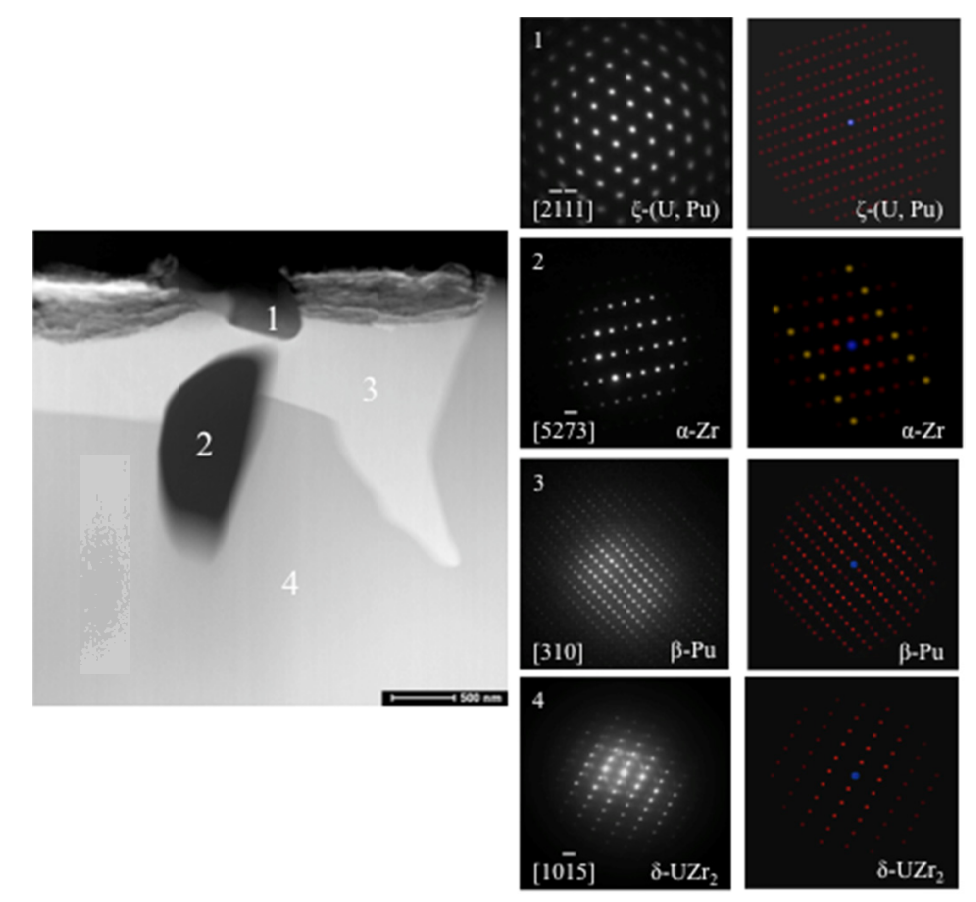

Figure 6. STEM micrograph and corresponding SAED patterns acquired from the middle of first cross-sectional lift-out.
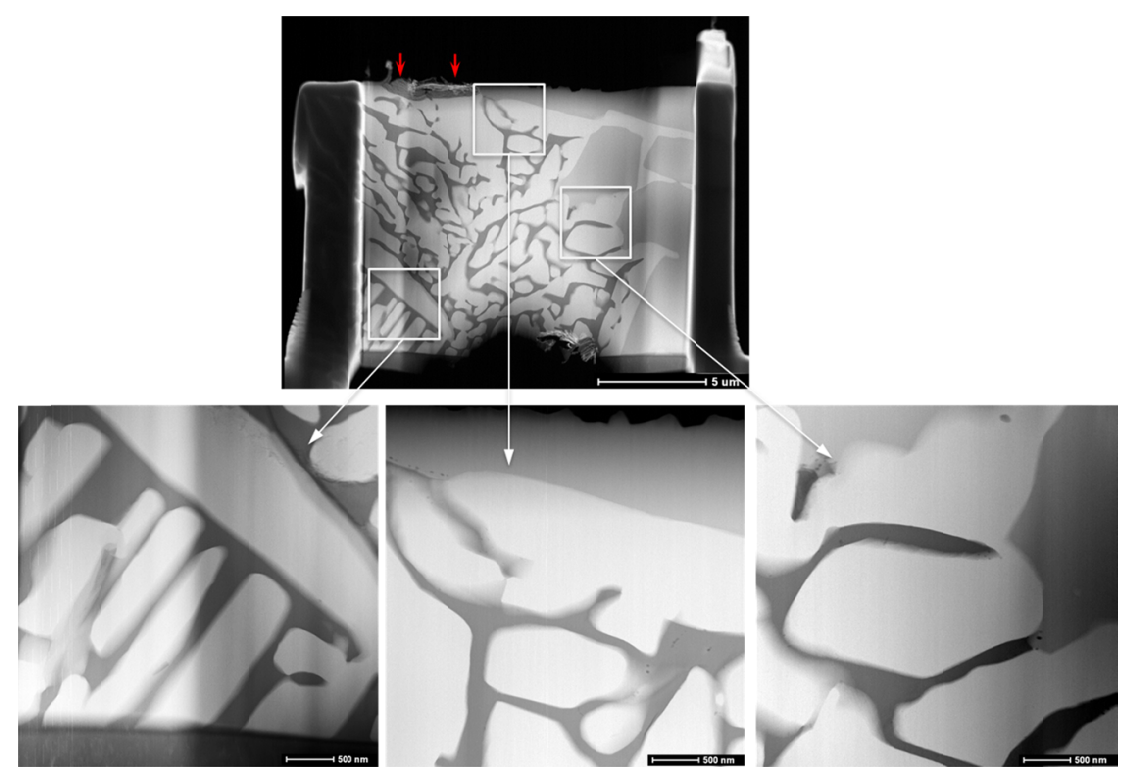

Figure 7. STEM micrographs providing an overview of the second cross-sectional specimen lifted-out from U-23Pu-9Zr fuel. Red arrows indicate location of the oxide layer.

An overview of the microstructure in the second lift-out is provided in Fig. 7. The microstructure of the second lift-out differs from the first. Even though the features on the surface look similar to the first lift-out - oxidation layer on top of the $\beta$-Pu phase that is located next to the $\delta-\mathrm{UZr}_{2}$ phase - more complex features form away from specimen surface. Figure 8 provides SAED patterns of the observed $\delta$-UZr $\mathrm{Ur}_{2}$ phase that forms on the surface of the specimen 
and matrix $\beta$-Pu phase. The ribbon-like dark contrast features seen in the STEM micrograph (Fig. 8) correspond to $\mathrm{U}_{0.5} \mathrm{Zr}_{0.5}$, also known as (U, $\left.\mathrm{Zr}\right) \mathrm{ht}$ phase. The existing phase diagrams and previously conducted work do not predict formation of $\beta$-Pu or $(\mathrm{U}, \mathrm{Zr}) \mathrm{ht}$ phases in these alloys. It can be attributed to the formation of an oxide layer on top of $\beta$-Pu that masks $\beta$-Pu presence during analysis with techniques that solely rely on surface information, such as XRD and SEM. The summary of all phases observed in this fuel is provided in Table 1 .

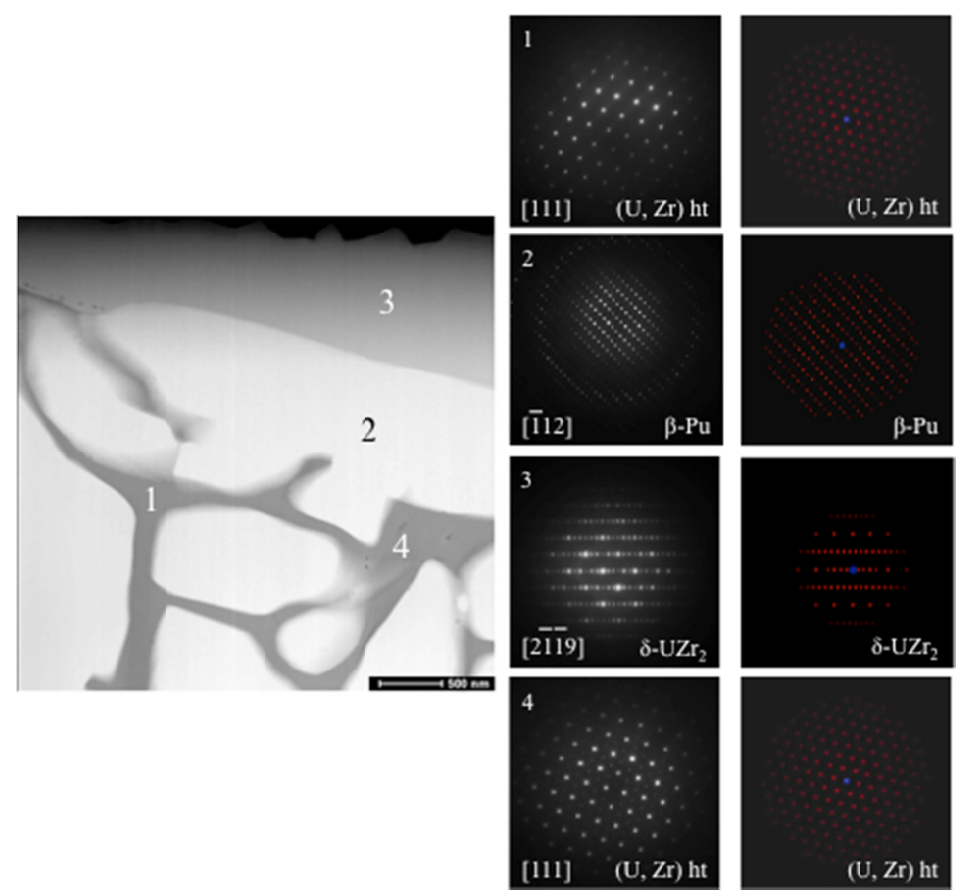

Figure 8. STEM micrograph and corresponding SAED patterns acquired from the top of second cross-sectional lift-out.

\begin{tabular}{|l|l|l|l|}
\hline Phase & Formula & Space group & Unit cell parameters, $\mathrm{nm}$ \\
\hline$\delta-\mathrm{UZr}_{2}$ & $\mathrm{UZr}_{2}$ & $\mathrm{P} 6 / \mathrm{mmm}(191)$ & $\mathrm{a}=\mathrm{b}=0.50317 ; \mathrm{c}=0.30888$ \\
\hline$\zeta-(\mathrm{U}, \mathrm{Pu})$ & $\mathrm{U}_{0.4} \mathrm{Pu}_{0.6}$ & $\mathrm{R}-3 \mathrm{~m}(166)$ & $\mathrm{a}=\mathrm{b}=1.50764 ; \mathrm{c}=1.85926$ \\
\hline$\beta-\mathrm{Pu}$ & $\mathrm{U}_{0.02} \mathrm{Pu}_{0.98}$ & $\mathrm{C} 12 / \mathrm{m} 1(12)$ & $\mathrm{a}=1.1818 ; \mathrm{b}=1.0418 ; \mathrm{c}=0.7815$ \\
\hline$(\mathrm{U}, \mathrm{Zr}) \mathrm{ht}$ & $\mathrm{U}_{0.5} \mathrm{Zr}_{0.5}$ & $\mathrm{Im}-3 \mathrm{~m}(229)$ & $\mathrm{a}=\mathrm{b}=\mathrm{c}=0.3546$ \\
\hline$\alpha-\mathrm{Zr}$ & $\mathrm{Zr}$ & $\mathrm{P} 6_{3} / \mathrm{mmc}(194)$ & $\mathrm{a}=\mathrm{b}=0.3216 ; \mathrm{c}=0.5154$ \\
\hline
\end{tabular}

Table 1. Summary of the phases observed in the fuel. 
Additional SAED patterns of the $\delta-\mathrm{UZr}_{2}, \beta-\mathrm{Pu}$, and $(\mathrm{U}, \mathrm{Zr}) \mathrm{ht}$ phases observed in the second lift-out specimen and the corresponding STEM micrograph are provided in Fig. 9. As it can be seen, $\delta$ - $\mathrm{UZr}_{2}$ and $(\mathrm{U}, \mathrm{Zr}) \mathrm{ht}$ phases overlap in two regions. It most likely can be attributed to thinning of $\delta-\mathrm{UZr}_{2}$ phase and formation of a slightly thicker $(\mathrm{U}, \mathrm{Zr}) \mathrm{ht}$ phase next to it. The contrast of $(\mathrm{U}, \mathrm{Zr}) \mathrm{ht}$ phase dominates in the two regions seen in Fig. 9. The observed bcc (U, $\mathrm{Zr}$ )ht phase is a high temperature phase that is stable down to $610^{\circ} \mathrm{C}$, where it overlaps with $\delta$ $\mathrm{UZr}_{2}$ phase. The $(\mathrm{U}, \mathrm{Zr}) \mathrm{ht}$ phase was most likely trapped by $\delta-\mathrm{UZr}_{2}$ and $\beta-\mathrm{Pu}$ phases during the cooling process. The binary U-Pu phase diagram indicates that $\beta$-Pu phase exists in a narrow band between 125 and $278^{\circ} \mathrm{C}$ and is formed due to the eutectoid reaction between $\alpha-\mathrm{Pu}$ and $\zeta-(\mathrm{U}$, $\mathrm{Pu}$ ) [18-19]. It is reasonable to assume that $\alpha-\mathrm{Pu}$ and majority of $\zeta-(\mathrm{U}, \mathrm{Pu})$ transform into $\beta-\mathrm{Pu}$ phase during cooling. This could explain why only a few $\zeta-(\mathrm{U}, \mathrm{Pu})$ precipitates and no $\alpha$-Pu were observed in the fuel alloy during examination. In summary, several phases have been found in $\mathrm{U}$ 23Pu-9Zr alloy during TEM analysis: $\zeta-(\mathrm{U}, \mathrm{Pu}), \delta$ - $\mathrm{UZr}_{2}, \beta-\mathrm{Pu},(\mathrm{U}, \mathrm{Zr}) \mathrm{ht}$, and $\alpha-\mathrm{Zr}$. Only three of these phases have been previously reported: $\alpha-\mathrm{Zr}, \zeta-(\mathrm{U}, \mathrm{Pu})$, and $\delta-\mathrm{UZr}_{2}$. Since majority of the previous reports used surface based analysis techniques, it is not surprising that $\beta$-Pu and $(\mathrm{U}$, $\mathrm{Zr}$ )ht phases have not been observed. Cross-sectional TEM specimens prepared in the FIB show the microstructure of the fuel beyond the surface layer.

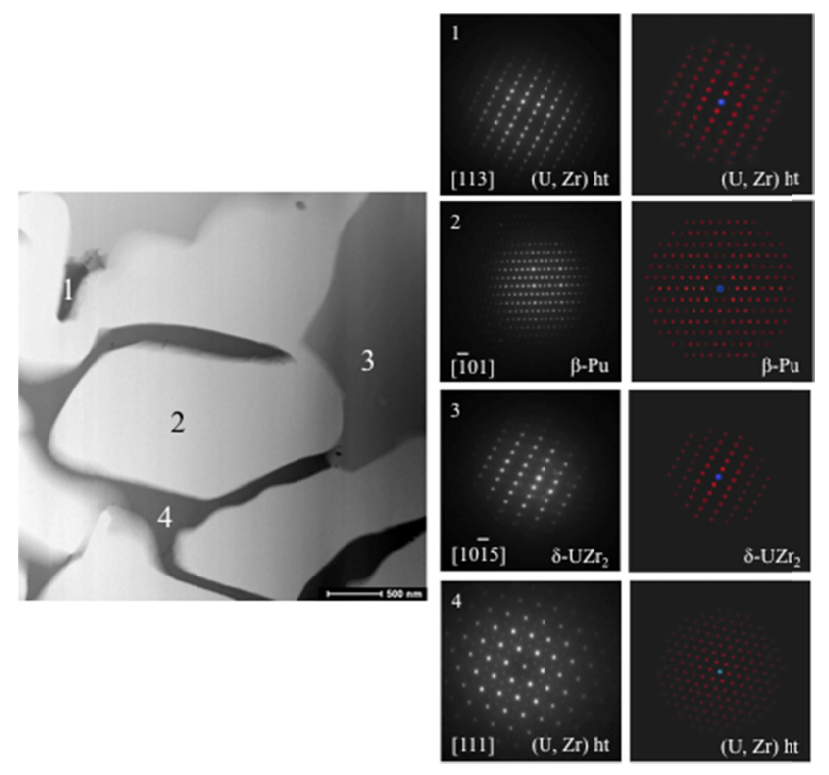

Figure 9. STEM micrograph and corresponding SAED patterns acquired from the right hand side of the second life-out specimen.

\section{Summary}

This paper identified and characterized phases formed in the U-23Pu-9Zr alloy. The study combined SEM and TEM examination of the alloy with electron diffraction data obtained using transmission electron microscopy. Initial SEM examination indicated formation of three phases in the fuel $-\mathrm{Zr}$ enriched globular inclusions, $\mathrm{U}$ and $\mathrm{Zr}$ enriched phase, and $\mathrm{U}$ enriched 
matrix. SEM examination was followed by detailed TEM analysis. Implementation of a FIB instrument allowed for the preparation of cross-sectional TEM specimens from these transuranic samples. The high spatial resolution of TEM data allowed for the determination of the structures of individual phases. The $U$ enriched matrix observed in SEM in fact corresponds to an oxide layer formed on top of the $\beta$-Pu phase. TEM examination showed that the matrix consists of $\delta$ $\mathrm{UZr}_{2}, \beta-\mathrm{Pu}$, and $(\mathrm{U}, \mathrm{Zr}) \mathrm{ht}$ phases, which could not be determined based on SEM analysis. Two types of small inclusions were observed in the fuel, which were consistent with $\alpha-\mathrm{Zr}$ and $\zeta$-(U, $\mathrm{Pu})$ phases. Sample annealing produced $\alpha-\mathrm{Zr}, \beta-\mathrm{Pu}$, and $(\mathrm{U}, \mathrm{Zr}) \mathrm{ht}$ phases as determined by SAED analysis, which are not indicated in the room temperature phase diagram for the alloy under study. The observed $\alpha-\mathrm{Zr}$ phase most likely formed because of the migration of $\mathrm{Zr}$ towards the oxygenated surface during heating of the specimen. Formation of $\beta-\mathrm{Pu}$ and $(\mathrm{U}, \mathrm{Zr}) \mathrm{ht}$ has not been previously reported. However, the majority of previous studies used surface based analysis techniques, such as XRD and SEM. The $\beta$-Pu phase is masked by a thick oxide layer formed on top of it. The $(\mathrm{U}, \mathrm{Zr}) \mathrm{ht}$ phase forms below the specimen surface and is typically masked by $\beta-\mathrm{Pu}$ and $\delta$ - $\mathrm{UZr}_{2}$.

\section{Acknowledgements}

This work is supported by the U.S. Department of Energy, Office of Nuclear Energy under DOE Idaho Operations Office Contract DE-AC07-05ID14517, as part of Fuel Cycle Research and Development (FCRD) program of US Department of Energy and Nuclear Science User Facilities.

\section{U.S. Department of Energy Disclaimer}

The U.S. Government retains a nonexclusive, royalty-free license to publish or reproduce the published form of this contribution, or allow others to do so, for U.S. Government purposes. This information was prepared as an account of work sponsored by an agency of the U.S. Government. Neither the U.S. Government nor any agency thereof, nor any of their employees, makes any warranty, express or implied, or assumes any legal liability or responsibility for the accuracy, completeness, or usefulness of any information, apparatus, product, or process disclosed, or represents that is use would not infringe privately owned rights. References herein to any specific commercial product, process, or service by trade name, trademark, manufacturer, or otherwise, does not necessarily constitute or imply its endorsement, recommendation, or favoring by the U.S. Government or any agency thereof. The views and opinions of authors expressed herein do not necessarily state or reflect those of the U.S. Government or any agency thereof. 


\section{References:}

1. D. E. Burkes, R. E. Fielding, D. L. Porter, J. Nucl. Mater. 392, 158 (2009).

2. G. L. Hofman, L. C. Walters, T. H. Bauer, Progress in Nucl. Energy 31, 83 (1997).

3. D. L. Porter, C. E. Lahm, R. G. Pahl, Metal. Trans. 21A, 1871 (1990).

4. Y. S. Kim, G. L. Hofman, S. L. Hayes, Y. H. Sohn, J. Nucl. Mater. 327, 27 (2004).

5. M. Kurata, Calphad 23, 305 (1999).

6. M. Kurata, K. Nakamura, T. Ogata, J. Nucl. Mater. 294, 123 (2001).

7. K. Nakamura, T. Ogata, M. Kurata, T. Yokoo, M. A. Mignanelli, J. Nucl. Mater. 304, 63 (2002).

8. Y. H. Sohn, M. A. Dayananda, G. L. Hofman, R. V. Strain, S. L. Hayes, J. Nucl. Mater. 279, 317 (2000).

9. G. L. Hofman, L. C. Walters, in: B. R. T. Frost (Ed.), Nuclear Materials, Part 1, vol. 10A VCH; in: R. W. Cahn, P. Haasen, E. J. Kramer (Eds.), Materials Science and Technology: A Comprehensive Treatment, VCH, Wrinheim, Germany, 1994.

10. R. D. Mariani et. al., Phase Studies and Property Measurements of Some Ternary Fuel Alloys, AFC2-B General Fuel Characterization Report, INL/EXT-09-16781, Idaho National Laboraoty (2009).

11. A. C. Lawson et. al., Acta Cryst. B52, 32 (1996).

12. D. R. O’Boyle, A. E. Dwight, Uranium-plutonium-zirconium ternary alloy system, in: Proc., $4^{\text {th }}$ International Conference on Plutonium and Other Actinides, 1970, pp720-732.

13. L. Leibowitz et. al., J. Nucl. Mater. 154, 145 (1998).

14. C. L. Trybus, J. E. Sanecki, S. P. Henslee, J. Nucl. Mater. 204, 50 (1993).

15. D. E. Janney, J. R. Kennedy, J. W. Madden, T. P. O’Holleran, J. Nucl. Mater. 448, 109 (2014).

16. D. E. Janney, J. R. Kennedy, J. W. Madden, T. P. O’Holleran, J. Nucl. Mater. 456, 46 (2015).

17. P. Stadelmann, JEMS (EMS Java version), in: CIME-EPFL, Lausanne, Switzerland, 2004.

18. H. Okamoto, J. Phase Equilib. 17, 372 b (1996).

19. H. Okamoto, Phase Diagrams for Binary Alloys, Desk Handbook, vol. 1, 2000. 


\section{Caption}

Figure 1. Extrapolated room temperature ternary U-Pu-Zr phase diagram [11]. The star identifies compositional point of U-23Pu-9Zr fuel.

Figure 2. Backscattered electron micrographs showing the microstructure of the fuel. Two BSE micrographs on the left are a higher magnification overview of the areas identified with white rectangles in the micrograph on the right. Two smaller rectangles identify positions of TEM liftouts.

Figure 3. Scanning electron micrograph and corresponding X-ray maps of the phases formed in ternary $\mathrm{U}-23 \mathrm{Pu}-9 \mathrm{Zr}$ system.

Figure 4. Scanning transmission electron micrographs providing an overview of the first crosssectional specimen lifted-out from U-23Pu-9Zr fuel. Red arrows indicate location of the oxide layer.

Figure 5. STEM micrograph acquired from the left hand side of first cross-sectional lift-out and corresponding experimental (middle row) and simulated SAED patterns (right row).

Figure 6. STEM micrograph and corresponding SAED patterns acquired from the middle of first cross-sectional lift-out.

Figure 7. STEM micrographs providing an overview of the second cross-sectional specimen lifted-out from U-23Pu-9Zr fuel. Red arrows indicate location of the oxide layer.

Figure 8. STEM micrograph and corresponding SAED patterns acquired from the top of second cross-sectional lift-out.

Table 1. Summary of the phases observed in the fuel.

Figure 9. STEM micrograph and corresponding SAED patterns acquired from the right hand side of the second life-out specimen. 